\title{
Assessment of genetic divergence for quantitative traits in thermo tolerant tomato (Solanum lycopersicum L.) genotypes
}

\author{
Manish Kumar $^{1 *}$, R. K. Yadav ${ }^{1}$, T. K. Behera ${ }^{1}$, Akshay Talukdar ${ }^{2}$ and Manpreet Kour ${ }^{1}$ \\ ${ }^{1}$ Division of Vegetable Science, ICAR-Indian Agricultural Research Institute, New Delhi-110012, INDIA \\ ${ }^{2}$ Division of Genetics and Plant Breeding, ICAR-Indian Agricultural Research Institute, New Delhi-110012, INDIA \\ *Corresponding author. E-mail: imanishkumar91@gmail.com
}

Received: December 20, 2016; Revised received: April 19, 2017; Accepted: January 10, 2018

\begin{abstract}
In the present study, 21 thermo tolerant tomato (Solanum lycopersicum L.) genotypes were evaluated to delineate the extent of genetic diversity through 10 quantitative traits. The genotypes were categorized into 4 distinct clusters using $D^{2}$ statistics. Cluster IV had the maximum number (10) of genotypes, where all heat tolerant genotypes grouped together, followed by cluster I (5). Intra cluster analysis revealed that the cluster IV had highest distance, while the inter cluster distance was maximum between cluster III and cluster IV (6.53) indicating the presence of wide range of variability among genotypes of the cluster. Cluster IV recorded maximum cluster mean for yield (579.0), average fruit weight (33.33) and fruit set per cent (54.8) and the cluster III recorded highest mean value for days to 50 percent flowering (67.33). Principal component analysis showed that the first two principal components (PC's) accounting for 77.6 per cent of total variation. On the basis of inter cluster distance, cluster mean and principal component analysis observed in the present study, a crossing programme involving genotypes from cluster IV will be promising one for developing heat tolerant tomato hybrids.
\end{abstract}

Keywords: Clustering pattern, $\mathrm{D}^{2}$ analysis, Genetic divergence, Principal component analysis, Solanum lycopersicum

\section{INTRODUCTION}

Tomato is one of the most popular, widely cultivated and versatile fruit vegetable grown extensively in the world. It has originated in the Peru-Equador region of the Andes in South America (Rick, 1969). In India, it ranks second among vegetables in area and production and occupies an area of 1.20 Million hectares with a production of 19.40 Million tonnes and productivity of 16.10 tonnes per hectare (National Horticulture Board, 2015). It can be consumed fresh as salads or after cooking and utilised in the preparation of wide range of processed products like paste, puree, sauce etc. Also, tomato is considered as one of the most important 'protective foods' because of its special nutritive value and health benefits. Tomatoes are rich source of fibers, Vitamin A, Vitamin C and minerals like Calcium, Iron and Phosphorous in human diet (Saleem et al., 2013). Tomato pulp and juice is digestible mild aperients, a promoter of gastric secretion and blood purifier. Apart from this, lycopene is valued for its anticancer property. It acts as an antioxidant, which is often associated with carcinogenesis.

Looking at its economic importance, there is always a need for improved varieties or hybrids in future for desirable agronomic traits. The present day breeding shifts to the identification and use of lines which are tolerant to abiotic stresses particularly high temperature stress when tomato crop is concerned. Also, tomato is highly amenable to genetic improvement owing to its high degree of homogeneity and ease of controlled pollination. Genetic diversity is the basic requirement for successful breeding programme. Collection and evaluation of germplasm lines and genotypes of any crop is a prerequisite for a breeding programme and provides a greater scope for exploiting genetic diversity (Vavilov, 1951). The multivariate analysis $\left(\mathrm{D}^{2}\right)$ is a powerful tool to measure the genetic divergence within a set of genotypes and rational choice of potential parents for hybridization in a breeding programme (Murthy and Arunachalam, 1966). The genetic improvement of tomato mainly depends upon the amount of genetic variability present in the population. Hence the present study aimed to estimate the genetic divergence and clustering pattern among twenty one thermo tolerant genotypes of tomato.

\section{MATERIALS AND METHODS}

Genetic evaluation of thermo tolerant tomato genotypes on the basis of morphological traits was performed in the Research Farm of Division of Vegetable Science, Indian Agricultural Research Institute, New Delhi (latitude $28^{\circ} 40^{\prime}$ North, longitude $77^{\circ} 12^{\prime}$ East 
and at an altitude of $228.6 \mathrm{~m}$ above mean sea level) during the summer season (March-June) of the year 2014. The climate of Delhi is semi-arid with hot summers and cool winters. The experimental material consisted of 21 contrasting thermo tolerant and diverse genotypes of tomato (Table 1) and the experiment was laid out in randomized block design with 3 replications. All the recommended cultural practices were followed to raise a healthy crop. Ten quantitative characters viz., leaf length $(\mathrm{cm})$, leaf width $(\mathrm{cm})$, days to 50 per cent flowering, In vitro pollen germination, average fruit weight $(\mathrm{g})$, fruit polar diameter $(\mathrm{cm})$, fruit equatorial diameter $(\mathrm{cm})$, pericarp thickness of fruit $(\mathrm{cm})$, fruit set per cent and yield per plant $(\mathrm{g})$ were taken into consideration for estimating genetic diversity. The mean values of five plants were taken for the analysis of genetic divergence following Mahalanobis (1936). The genotypes were grouped into different clusters following Tocher's method as described by Rao (1952). The average intra and inter cluster distances and contribution of characters towards genetic divergence were estimated by using the method as described by Singh and Chaudhary (1977).

\section{RESULTS AND DISCUSSION}

Twenty one tomato genotypes were analysed for genetic divergence following Mahalanobis $\mathrm{D}^{2}$ statistical procedure. The $\mathrm{D}^{2}$ values which determine the statistical distance among various genotypes reflecting their genetic diversity were estimated for each pair of genotypes under study. 21 genotypes were categorized into into 4 distinct clusters using $\mathrm{D}^{2}$ statistics based on morphological traits (Table 2). All the wild genotypes and exotic collections were grouped into cluster I and cluster III (Spr-1, Spr-2, Spm, SPM 1, SPM 2, SPM 3 and SPM 4). Cluster IV comprised of 10 genotypes

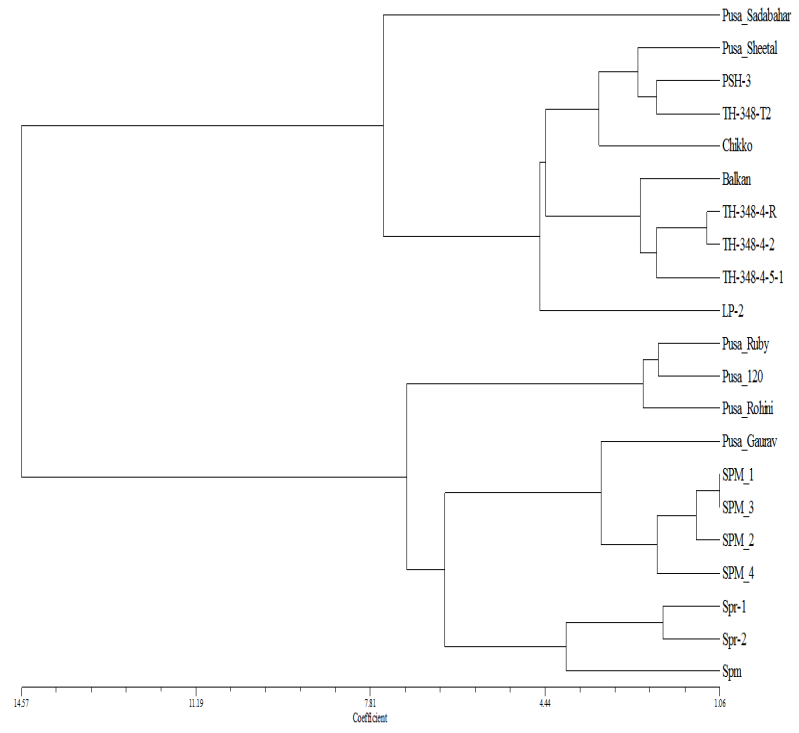

Fig. 1. Dendrogram showing clustering pattern among 21 thermo tolerant tomato genotypes for morphological traits. represented by heat tolerant genotypes namely Pusa Sadabahar, Pusa Sheetal, Chikko, LP-2, PSH-3, TH348-T2, Balkan, TH-348-4-R, TH-348-4-2, TH-348-45-1, while cluster II showed 4 heat sensitive genotypes namely Pusa Ruby, Pusa 120, Pusa Rohini and Pusa Gaurav.

Average intra (diagonal) and inter cluster distance of different clusters (Table 3) indicated that maximum intra cluster distance (1.94) was recorded in cluster IV, while the inter cluster distance was maximum (6.53) between cluster III and cluster IV followed by cluster II and cluster III (5.70). The maximum inter cluster distance showed the presence of greater divergence in these clusters, while maximum intra cluster distance showed the presence of greater divergence within the cluster. The above report is a kin with the findings of Singh et al. (2008) in tomato. Reddy et al. (2013) also reported maximum inter cluster distance between the cluster III and IV while studying the genetic diversity among 19 genotypes of tomato.

Cluster means of different genotypes (Table 4) indicated that genotypes in cluster I exhibited minimum cluster mean for fruit equatorial diameter (2.3) and maximum for days to $50 \%$ flowering (55.8). Similarly genotypes in cluster IV recorded maximum cluster mean for yield (579.0). The lines fall in to same cluster having lowest degree of divergence (Fig. 1) while, the lines fall in to divergent clusters will produce transgressive segregants when selected for parents in breeding programme. Sharma et al. (2006) also reported maximum cluster mean for yield per plant among 60 genotypes of tomato.

The Jaccard's similarity matrix was subjected to principal component analysis. This coordination method makes use of multidimensional solution of the observed relationships. Principal component analysis

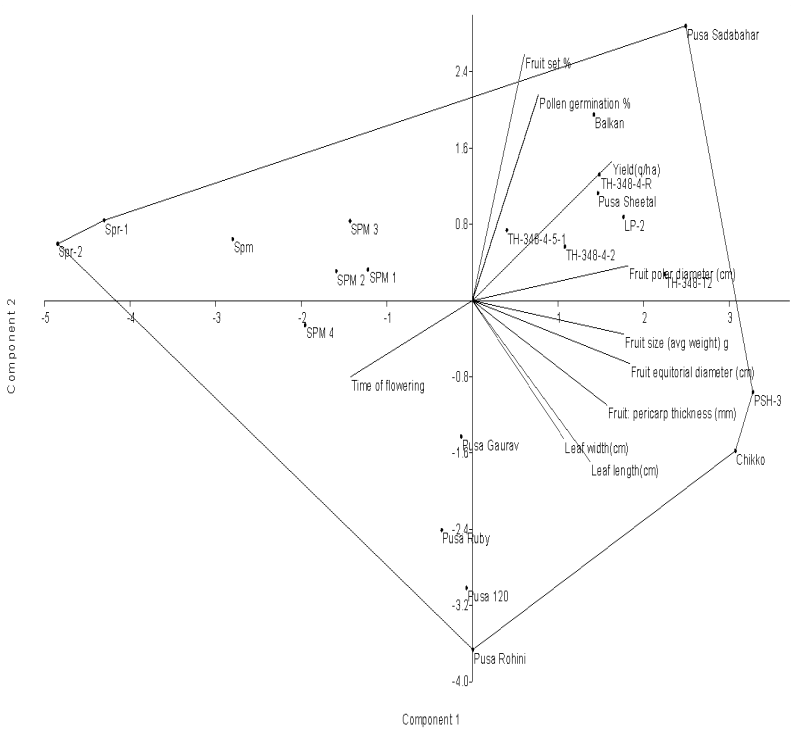

Fig. 2. Principal component analysis of 21 thermo tolerant tomato genotypes revealed by morphological traits. 
Manish Kumar et al. / J. Appl. \& Nat. Sci. 10 (1): 55 - 58 (2018)

Table 1. Different released varieties and genotypes of tomato included in the present experiment.

\begin{tabular}{llllll}
\hline Sl. No. & Varieties/genotypes & Tolerance level & Sl. No. & Varieties/genotypes & Tolerance level \\
\hline 1. & Pusa Sadabahar & HT & 12. & TH-348-4-R & HT \\
2. & Pusa Ruby & HS & 13. & TH-348-4-2 & HT \\
3. & Pusa 120 & HS & 14. & TH-348-4-5-1 & HT \\
4. & Pusa Rohini & HS & 15. & Spr-1 $*$ & HT \\
5. & Pusa Gaurav & HS & 16. & Spr-2* & HT \\
6. & Pusa Sheetal & HT & 17. & Spm** & HT \\
7. & Chikko & HT & 18. & SPM 1** & HT \\
8. & LP-2 & HT & 19. & SPM 2** & HT \\
9. & PSH-3 & HT & 20. & SPM 3** & HT \\
10. & TH-348-T2 & HT & 21. & SPM 4** & HT \\
11. & Balkan & HT & & & \\
\hline
\end{tabular}

Where HT- heat tolerant, HS- heat sensitive and $*$ S.peruvianum, ${ }^{* *}$ S. pimpinellifolium

Table 2. Clustering pattern of 21 thermo tolerant tomato genotypes based on Mahalanobis $\mathrm{D}^{2}$ statistics.

\begin{tabular}{lll}
\hline Clusters & No. of genotypes & Name of genotypes \\
\hline I & 5 & Spm, SPM-1, SPM-2, SPM-3, SPM-4 \\
II & 4 & Pusa Ruby, Pusa 120, Pusa Rohini, Pusa Gaurav \\
III & 2 & Spr-1, Spr-2 \\
IV & 10 & $\begin{array}{l}\text { Pusa Sadabahar, Pusa Sheetal, Chikko, LP-2, PSH-3, TH-348-T2, Balkan, TH-348-4-R, TH } \\
\end{array}$ \\
\end{tabular}

Table 3. Estimates of average intra (diagonal) and inter cluster distance for different clusters for morphological traits of 21 thermo tolerant tomato genotypes under heat stress.

\begin{tabular}{lllll}
\hline Clusters & I & II & III & IV \\
\hline I & 1.358 & & & \\
II & 3.663 & 1.299 & & \\
III & 3.631 & 5.701 & 0.676 & \\
IV & 3.898 & 3.928 & 6.532 & 1.947 \\
\hline
\end{tabular}

(PCA) resolves complex relationships into interactions of fewer and simpler factors. In this technique, the data matrix is derived from the distances (or similarities) between the operational taxonomic units. The principal component analysis of the morphological traits is presented in (Table 5, Fig 2). The first 2 PC's having eigen value more than one accounting for $77.6 \%$ of total variation based on morphological traits. PC-1 showed positive factor loading for leaf length $(0.30)$, pollen

Table 4. Cluster mean of morphological traits of 21 thermo tolerant tomato genotypes under heat stress.

\begin{tabular}{|c|c|c|c|c|c|c|c|c|}
\hline \multirow[t]{2}{*}{ Cluster Traits } & \multicolumn{2}{|l|}{ I } & \multicolumn{2}{|l|}{ II } & \multicolumn{2}{|l|}{ III } & \multicolumn{2}{|l|}{ IV } \\
\hline & Mean & $\mathbf{S E} \pm$ & Mean & $\mathbf{S E} \pm$ & Mean & $\mathbf{S E} \pm$ & Mean & $\mathbf{S E} \pm$ \\
\hline Leaf length $(\mathrm{cm})$ & 3.21 & 0.73 & 6.14 & 0.54 & 2.54 & 1.09 & 5.3 & 1.4 \\
\hline Leaf width $(\mathrm{cm})$ & 2.72 & 0.55 & 3.41 & 0.63 & 2.08 & 0.04 & 3.21 & 0.94 \\
\hline Days to $50 \%$ flowering & 55.8 & 4.3 & 59.5 & 1.11 & 67.33 & 1.41 & 53.77 & 3.32 \\
\hline Pollen germination $\%$ & 38.8 & 4.03 & 35.75 & 4.15 & 42.5 & 4.01 & 45.63 & 2.62 \\
\hline Avg. fruit weight $(\mathrm{g})$ & 20 & 2.94 & 29.09 & 5.82 & 12.49 & 0.01 & 33.33 & 6.25 \\
\hline Fruit polar diameter $(\mathrm{cm})$ & 2.62 & 0.23 & 2.63 & 0.21 & 0.98 & 0.01 & 3.62 & 0.6 \\
\hline Fruit equatorial diameter $(\mathrm{cm})$ & 2.3 & 0.26 & 3.25 & 0.17 & 0.91 & 0.01 & 3.31 & 0.37 \\
\hline Fruit pericarp thickness (mm) & 2.6 & 0.38 & 5.6 & 1.01 & 2.45 & 0.21 & 5.24 & 0.89 \\
\hline Fruit set $\%$ & 47.8 & 3.49 & 31.25 & 5.49 & 46.5 & 2.12 & 54.8 & 6.98 \\
\hline Yield/plant (g) & 182.20 & 11.59 & 295.00 & 15.2 & 165.20 & 9.36 & 579.00 & 18.31 \\
\hline
\end{tabular}

Table 5. Principal component analysis for morphological traits in 21 thermo tolerant tomato genotypes under heat stress

\begin{tabular}{|c|c|c|c|c|c|c|c|c|c|c|}
\hline Parameters & PC1 & PC2 & PC3 & PC4 & PC5 & PC6 & PC7 & PC8 & PC9 & PC10 \\
\hline Eigen value (root) & 5.11 & 2.65 & 0.88 & 0.66 & 0.33 & 0.14 & 0.09 & 0.06 & 0.05 & 0.03 \\
\hline Cumulative eigen value & 5.11 & 7.76 & 8.64 & 9.29 & 9.62 & 9.76 & 9.85 & 9.91 & 9.97 & 10.00 \\
\hline Explained variation $(\%)$ & 51.07 & 26.54 & 8.77 & 6.56 & 3.28 & 1.40 & 0.90 & 0.62 & 0.53 & 0.32 \\
\hline Cumulative explained variation $(\%)$ & 51.07 & 77.61 & 86.38 & 92.94 & 96.22 & 97.62 & 98.52 & 99.14 & 99.67 & 99.99 \\
\hline \multicolumn{11}{|l|}{ Eigen vectors } \\
\hline & PC1 & $\mathrm{PC} 2$ & PC3 & $\mathrm{PC} 4$ & PC5 & PC6 & PC7 & PC8 & PC9 & PC10 \\
\hline Leaf length $(\mathrm{cm})$ & 0.30 & 0.23 & -0.31 & 0.17 & 0.39 & 0.39 & 0.40 & 0.34 & 0.13 & 0.36 \\
\hline Leaf width $(\mathrm{cm})$ & -0.37 & -0.32 & -0.17 & 0.47 & -0.07 & 0.08 & -0.14 & -0.24 & 0.56 & 0.32 \\
\hline Days to $50 \%$ flowering & -0.37 & -0.61 & -0.25 & -0.41 & 0.31 & 0.28 & 0.19 & 0.056 & -0.14 & -0.18 \\
\hline Pollen germination $\%$ & 0.01 & -0.34 & 0.71 & 0.34 & 0.33 & 0.007 & -0.06 & 0.37 & -0.09 & 0.05 \\
\hline Avg. fruit weight (g) & 0.19 & -0.33 & -0.25 & -0.14 & -0.30 & -0.49 & 0.01 & 0.61 & 0.19 & 0.13 \\
\hline Fruit polar diameter $(\mathrm{cm})$ & 0.31 & -0.33 & 0.01 & 0.29 & -0.15 & -0.21 & 0.67 & -0.39 & -0.16 & -0.08 \\
\hline Fruit equatorial diameter $(\mathrm{cm})$ & -0.32 & 0.19 & 0.29 & -0.04 & -0.47 & 0.30 & 0.44 & 0.28 & 0.31 & -0.29 \\
\hline Fruit pericarp thickness (mm) & -0.25 & 0.07 & 0.29 & -0.41 & -0.05 & -0.16 & 0.25 & -0.15 & -0.08 & 0.74 \\
\hline Fruit set $\%$ & 0.58 & -0.25 & 0.25 & -0.39 & -0.07 & 0.32 & -0.15 & -0.23 & 0.45 & 0.02 \\
\hline Yield/plant (g) & -0.09 & 0.20 & 0.08 & -0.15 & 0.54 & -0.49 & 0.20 & -0.10 & 0.51 & -0.27 \\
\hline
\end{tabular}


germination $(0.01)$, fruit weight $(0.19)$, fruit polar diameter (0.31) and fruit set\% (0.58). Contribution of fruit set per cent was highest in PC-1. Emami and Eivazi (2013) explained $97 \%$ of total variations by the first two principal components among twenty-five tomato genotypes. Iqbal et al. (2014) also reported $81.72 \%$ of total variability for different traits by first three PCs among 47 tomato genotypes studied. Henareh et al. (2015) explained $71.6 \%$ of total variations by the first three components among 97 tomato genotypes. Genotypes belonging to cluster I and III are complementary to cluster II for most of the characters including sensitivity to high temperature in the present study. Hence these genotypes can be utilised for the development of varieties/ hybrids suitable for areas prevailing high temperature stress.

\section{Conclusion}

From the present study it was noted that all the varieties and genotypes were grouped into different clusters. All the thermo tolerant genotypes (Pusa Sadabahar, Pusa Sheetal, Chikko, LP-2, PSH-3, TH-348T2, Balkan, TH-348-4-R, TH-348-4-2, TH-348-4-5-1, Spr-1, Spr-2, Spm, SPM 1, SPM 2, SPM 3 and SPM 4) and thermo sensitive genotypes (Pusa Ruby, Pusa 120, Pusa Rohini and Pusa Gaurav) were represented by distinct clusters, indicating that clustering was done effectively. Thus, the present experiment provides useful information about thegenotypes/varieties belonging to different clusters, which upon crossing are likely to yield desirable recombinants. To have better recombinants, the hybridization between genotypesin cluster III and cluster IV which depicts maximum inter cluster distance (6.53); will be useful for exploitation of heterosis for yield and its components traits.

\section{REFERENCES}

Emami, A. and Eivazi, A.R. (2013). Evaluation of genetic variations of tomato genotypes (Solanum lycopersicum
L.) with multivariate analysis. Int. J. Sci. Res. Environ. Sci.,1: 273-284.

Henareh, M., Dursun, A. and Mandoulakani, B.A. (2015). Genetic diversity in tomato landraces collected from Turkey and Iran revealed by morphological characters. Acta Scientiarum Polonorum. Hortorum Cultus., 14: 269-291.

Iqbal, Q., Saleem, M.Y., Hameed, A. and Asghar, M. (2014). Assessment of genetic divergence in tomato through agglomerative hierarchical clustering and principal component analysis. Pak. J. Bot., 46: 1865 1870.

Mahalanobis, P.C. (1936). On the generalized distance in statistics. Proceedings of National Academic Science (India)., 2: 79-85.

Murthy, B.R. and Arunachalam, V. (1966). The nature of genetic divergence in relation to breeding system in crop plants. Indian J. Genet., 26: 188-189.

NHB (National Horticulture Board). (2015). [Available online]www.nhb.gov.in./area-pro/HB_Database_2015.

Rao, C.R. (1952). Advanced Statistical Methods in Biometric Research. John Willey \& Sons, New York, USA. pp.357 -363 .

Reddy, B.R., Reddy, M.P., Begum, H. and Sunil, N. (2013). Genetic diversity studies in tomato (Solanum lycopersicum L.). J. Agric. Veterinary Sci., 4:53-55.

Rick, C.M. (1969). Origin of cultivated tomato, current status of the problem. Abstract XI, International Botanical Congress. pp. 180.

Saleem, M.Y., Asghar, M., Iqbal, Q., Rahman, A. and Akram, M. (2013). Diallel analysis of yield and some yield components in tomato (Solanum lycopersicum L.). Pak. J. Bot., 45(4): 1247-1250.

Sharma, H.R., Sharma, D. and Thakur, A.K. (2006). Analysis of genetic divergence in tomato (Lycopersicon esculentum Mill.). J. Hort. Sci., 1(1): 52-54.

Singh, A.K., Sharma, J.P., Kumar, S. and Chopra, S. (2008). Genetic divergence in tomato (Lycopersicon esculentum Mill.). J. Res.,7: 1-8.

Singh, P.K. and Chaudhary, R.D. (1977). Biometrical methods in quantitative genetic analysis, Kalyani Publishers, New Delhi. pp.178-185.

Vavilov, N.I. (1951). The origin, variation, immunity and breeding of cultivated plant. Soil Sci., 72: 482. 